\title{
Pituitary Adenoma Presenting As Trigeminal Neuralgia
}

\author{
Abrar A. Wani ${ }^{1} \quad$ Altaf U. Ramzan ${ }^{1} \quad$ Abdul Q. Khan ${ }^{1} \quad$ Nayil K. Malik ${ }^{1} \quad$ Khalid Pervez $^{1}$ \\ ${ }^{1}$ Department of Neurosurgery, Sher-i-Kashmir Institute of Medical \\ Sciences (SKIMS), Srinagar, Jammu \& Kashmir, India \\ Indian J Neurosurg 2017;6:220-222.

\begin{abstract}
Address for correspondence Abrar A. Wani, MCh, Department of Neurosurgery, Sher-i-Kashmir Institute of Medical Sciences (SKIMS), Soura, Srinagar, Jammu \& Kashmir, India
\end{abstract} \\ (e-mail: drabrarahadwani@gmail.com).
}
Abstract
Keywords
- pituitary
- trigeminal
- neuralgia
- tumor

Compression of trigeminal nerve in cavernous sinus leading to trigeminal neuralgia is one of the rare presentations of pituitary tumor. We report a patient whose presenting complaint was trigeminal neuralgia in V1, V2 distribution and he had pituitary macroadenoma invading ipsilateral cavernous sinus. After surgery, the neuralgia disappeared completely.

\section{Introduction}

Trigeminal neuralgia (TN) is one of the most severe pains known and was first described by John Fothergill in $1773 .{ }^{1}$ The most common etiology of trigeminal neuralgia is microvascular compression of trigeminal nerve in its course in posterior fossa. Various tumors have been known to cause trigeminal neuralgia by compression of nerve which includes schwanoma, lipoma, epidermoid, meningioma, chordoma, granuloma, metastasis, and glioblastoma. ${ }^{2-5}$ Among all the tumors, compression of trigeminal nerve or its one or more divisions in cavernous sinus by pituitary adenoma is a rare entity. On literature search in PubMed and Medline, we could find only one case of pituitary adenoma compressing V1, V2 in cavernous sinus and leading to trigeminal neuralgia. ${ }^{6}$

\section{Case Report}

A middle-aged person presented with episodic paroxysmal attacks of sharp pain in left V1, V2 divisions and was administered carbamazepine which was gradually increased over a period of few weeks to $1,200 \mathrm{mg}$ per day. He complained of similar type of pain, and an MRI of brain was done which revealed a pituitary macroadenoma involving left cavernous sinus (see - Fig. 1). Visual acuity was $6 / 9$ and $6 / 36$ for right and left sides, respectively. This diminution of vision was gradual and not sudden. Hormonal workup revealed the tumor as nonfunctional. He was operated by transnasal trans-sphenoidal route. Tumor was soft, grayish with some fluid-filled cystic regions.

The cavernous sinus was not disturbed as tumor was soft and could be removed easily from lateral sides. In postoperative period, he was relieved of neuralgia. Histopathological examination confirmed the tumor as pituitary adenoma.

\section{Discussion}

The pathophysiology of the headache associated with pituitary tumors is less clear. Dural stretch, invasion of the cavernous sinus, and local compression effects are the possible mechanisms. ${ }^{7,8}$ It has been seen that differences in tumor size were not apparent between those who presented headaches and those who did not. Also, there was no clear relationship between the pituitary volume and headache score. ${ }^{8,9}$ Many patients report headaches after starting pharmacotherapy for adenoma; one explanation given for why headaches get worse after taking dopamine agonist is that the growth of the tumor is transitory or that a neurohormonal mechanism is possible. ${ }^{10,11}$ The degree of extension into the cavernous sinus is not associated with the presence or extent of headache. received

April 9, 2015

accepted

September 17, 2016

published online

September 11, 2017
DOI https://doi.org/

10.1055/s-0036-1596043. ISSN 2277-954X.

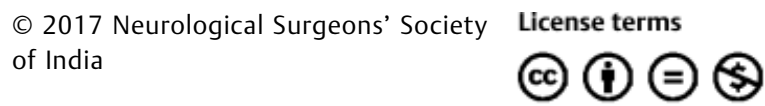




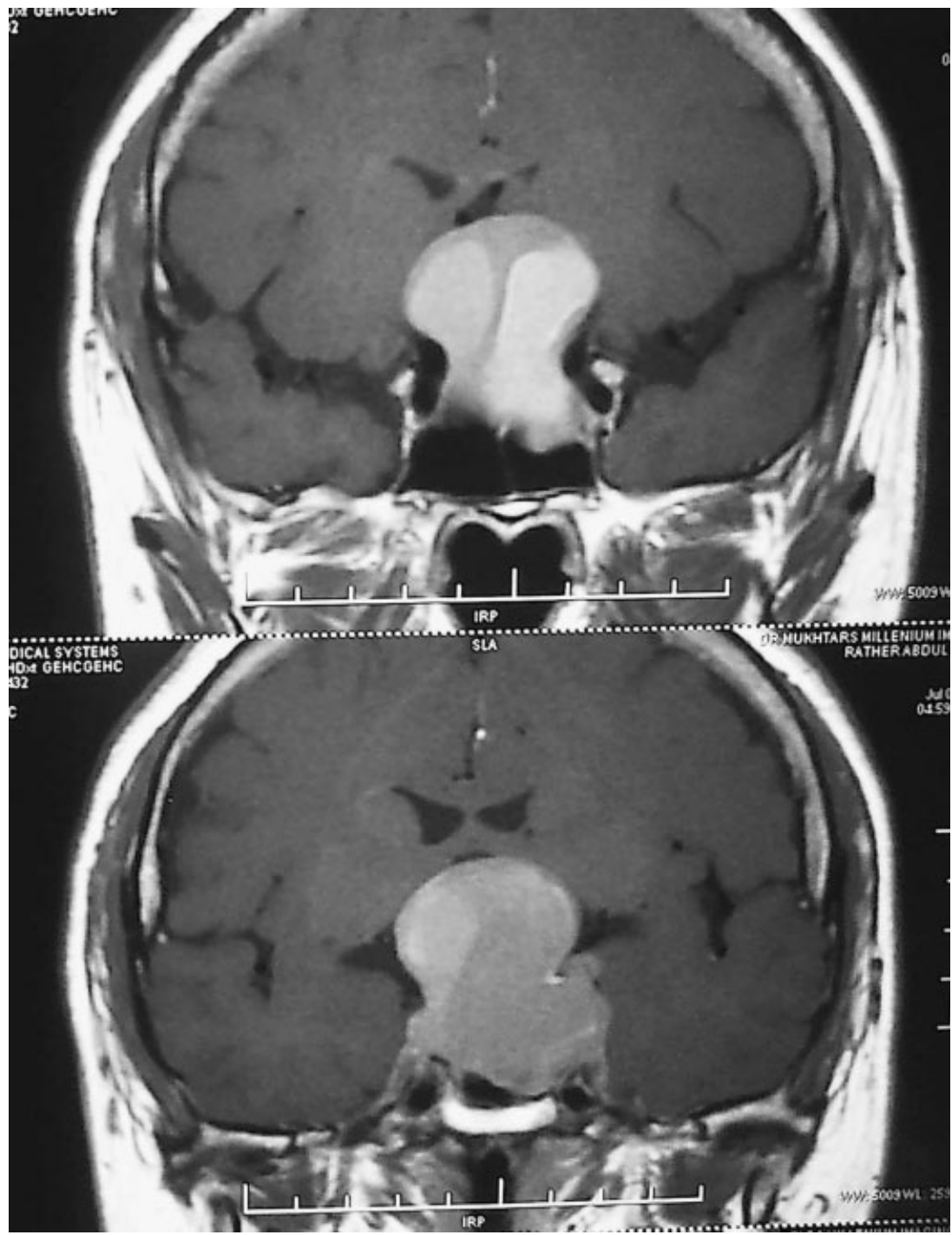

Fig. 1 Coronal CEMRI brain showing pituitary macroadenoma with extension into left cavernous sinus.

Management of trigeminal neuralgia can be either medical or surgical. Carbamazepine is the drug of choice for the treatment of TN. The therapeutic doses range from 600 to $1,200 \mathrm{mg}$ per day. The second option for the management of TN includes phenytoin, baclofen, valproate, and gabapentin. The other options in idiopathic trigeminal neuralgia range from gold standard microvascular decompression to alcohol block of the peripheral branch of trigeminal nerve, percutaneous radiofrequency thermocoagulation of the trigeminal nerve sensory root, and gamma knife. ${ }^{12-14}$ However, in patients with tumor, decompression alone seems to be the treatment, and for pituitary adenomas trans-sphenoidal decompression seems to be the best option.

\section{Conclusion}

The pituitary adenoma presenting as trigeminal neuralgia is an extremely rare presentation, and the patients can be managed by trans-sphenoidal route only.

\section{References}

1 Pareja JA, Shen JM, Kruszewski P, Caballero V, Pamo M, Sjaastad O. SUNCT syndrome: duration, frequency, and temporal distribution of attacks. Headache 1996;36(3):161-165

2 Borne G. Trigeminal neuralgia as the presenting symptom of a tuberculoma of the cerebellopontine angle. Case report. J Neurosurg 1968;28(5):480-482

3 Du R, Binder DK, Halbach V, Fischbein N, Barbaro NM. Trigeminal neuralgia in a patient with a dural arteriovenous fistula in Meckel's cave: case report. Neurosurgery 2003;53(1):216-221, discussion 221

4 Fritz C, Rösler A, Heyden B, Braune HJ. Trigeminal neuralgia as a clinical manifestation of Lyme neuroborreliosis. J Neurol 1996; 243(4):367-368

5 Delitala A, Brunori A, Chiappetta F. Trigeminal neuralgia resulting from infarction of the root entry zone of the trigeminal nerve: case report. Neurosurgery 1999;45(1):202

6 Gazioğlu N, Tanriöver N, Tüzgen S. Pituitary tumour presenting with trigeminal neuralgia as an isolated symptom. $\mathrm{Br} \mathrm{J}$ Neurosurg 2000;14(6):579

7 Friedman AH, Wilkins RH, Kenan PD, Olanow CW, Dubois PJ. Pituitary adenoma presenting as facial pain: report of two cases and review of the literature. Neurosurgery 1982;10(6 Pt 1):742-745 
8 Arafah BM, Prunty D, Ybarra J, Hlavin ML, Selman WR. The dominant role of increased intrasellar pressure in the pathogenesis of hypopituitarism, hyperprolactinemia, and headaches in patients with pituitary adenomas. J Clin Endocrinol Metab 2000;85(5): 1789-1793

9 Abe T, Matsumoto K, Kuwazawa J, Toyoda I, Sasaki K. Headache associated with pituitary adenomas. Headache 1998;38(10): 782-786

10 Ferrari MD, Haan J, van Seters AP. Bromocriptine-induced trigeminal neuralgia attacks in a patient with a pituitary tumor. Neurology 1988;38(9):1482-1484
11 Levy MJ, Matharu MS, Goadsby PJ. Prolactinomas, dopamine agonists and headache: two case reports. Eur J Neurol 2003; 10(2):169-173

12 Shakur SF, Bhansali A, Mian AY, Rosseau GL. Neurosurgical treatment of trigeminal neuralgia. Dis Mon 2011;57(10): 570-582

13 Elias WJ, Burchiel KJ. Trigeminal neuralgia and other neuropathic pain syndromes of the head and face. Curr Pain Headache Rep 2002;6(2):115-124

14 Fahlbusch R, Buchfelder M. Transsphenoidal surgery of parasellar pituitary adenomas. Acta Neurochir (Wien) 1988;92(1-4):93-99 